\title{
Changes in antagonistic activity of lactic acid bacteria induced by their response to technological factors
}

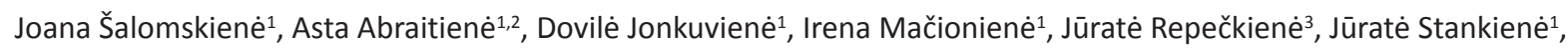 \\ Lina Vaičiulytè-Funk ${ }^{1}$ \\ ${ }^{1}$ Kaunas University of Technology, Food Institute, Taikos av. 92, Kaunas, Lithuania \\ ${ }^{2}$ Vilnius University, Institute of Biotechnology, V. Graičiūno str. 8, Vilnius, Lithuania \\ ${ }^{3}$ Nature Research Center, Institute of Botany, Žaliụjų ežerų str. 49, Vilnius, Lithuania \\ e-mail: dovile.jonkuviene@yahoo.com
}

\begin{abstract}
This study examined the changes in antagonistic activity of selected lactic acid bacteria (LAB) in response to technological factors used in food production. The antimicrobial activity of 12 selected LAB strains was assessed against the bacterial and fungal strains using the agar well diffusion method. Sodium chloride $(\mathrm{NaCl}) 6.5-8.0 \%$, glucose $20-30 \%$ and $\mathrm{pH} 4.0, \mathrm{pH} 8.0$ and higher were the most crucial factors in reducing the spectra of the microorganisms antagonized. Heating at $80^{\circ} \mathrm{C}$ or $100^{\circ} \mathrm{C}$ had a greater negative impact than $63^{\circ} \mathrm{C}$ on the antifungal activity of LAB. Freezing at $-72^{\circ} \mathrm{C}$ eliminated the antifungal activity, or it changed from fungicidal to fungistatic. Although each $L A B$ demonstrated the ability to retain antimicrobial activity induced by various technological factors, Lactococcus lactis $768 / 5$ was superior in retaining high antimicrobial activity against tested indicator strains.
\end{abstract}

Key words: lactic acid bacteria, antimicrobial activity, impact, technological factors, antimicrobial substances

\section{Introduction}

Recently, lactic acid bacteria (LAB) have been studied very intensively for their potential use as safe and natural food preservatives. Many studies focused on the antibacterial activity of LAB while less research has been done concerning the antifungal effect of $L A B$ strains. Only a few studies have dealt with both the antibacterial and antifungal activities of the same LAB strains in complex (Çakir 2010, Smaoui et al. 2010, Stoyanova et al. 2010, Šalomskienè et al. 2014).

Abundant screenings of novel LAB strains with improved antagonistic activity were carried out under the very close to optimal chemical environment. However, in reality, the growth of LAB may be confronted by lots of changes in the chemical environment because of the wide range of possible media compositions in vivo. For the selected LAB strains, it may be very important not only to survive unfavourable conditions but also to express the desired degree of activity against the harmful bacteria and fungi. However, full evidence has not been obtained to define the range of diversity induced by crucial environmental pressure on the capability of LAB to maintain their antagonistic activity. Comprehensive information about the ability of LAB to ensure efficient antagonistic activity under an altered initial chemical environment could be especially important for starter cultures in order to inhibit spoilage and pathogenic microorganisms. Traditional food ingredients such as $\mathrm{NaCl}$, glucose in various amounts as well as active acidity are often faced by LAB. They could be unfavourable for growth and metabolic activity of bacteria or human consumption but necessary for the technological process or taste qualities.

After reviewing the numerous efforts conducted to find natural tools to prevent bacterial and fungal growth, Lucera et al. (2012) pointed out that foods preserved with natural additives have become very popular, but sometimes the antagonistic activity of the single measure or additive in food preservation is not sufficient. The combination of nisin (the practically applied bacteriocin) with chemicals such as ethylenediamine tetra-acetic acid (EDTA) or chelating agents was able to increase the effectiveness of natural antagonistic activity along with additional exposure to harsh physical treatment (Gálvez et al. 2007). The addition of more than one organic acid used for food preservation improved the antagonistic activity across an increasing spectra of suppressed harmful microorganisms (Theron et al. 2010). A process involving the addition of an EDTA (0.02\%) and ascorbic acid combination and refrigerated storage at $\left(5^{\circ} \mathrm{C}\right)$ in darkness was reported as the most positive for controlling the spoilage of fish and fish products (Ghaly et al. 2010). Thus, in spite of many natural and synthetic chemicals employed in food preservation, there are still some difficulties faced in keeping the desired food safety and quality. Food preservation has become even more challenging as extensively applied preservatives are being confronted by pathogens or other harmful microorganisms. 
An increasing number of microbial species are becoming resistant to certain preservatives. Fungal human pathogens and spoilage moulds in food and feed systems are becoming resistant to preservatives such as sorbic and benzoic acids and potassium sorbate, as well as chemical treatment with cleaning compounds (Schnürer and Magnusson 2005). Blagojev et al. (2012) concluded that there is a great risk that the resistance phenomenon will increase because of the frequent use of antibiotics and preservatives. This conclusion was arrived at after the review of the ability of Penicillium, Saccharomyces and Zygosaccharomyces species to grow in the presence of potassium sorbate; of other moulds to degrade sorbate; and of Penicillium roqueforti to resist benzoate. Bacteria can have noninducible resistance mechanisms against organic acid compounds and, in some cases, microorganisms are able to degrade the added preservatives by making use of specific enzymes.

This study examined the potential of exploiting natural preservation induced by LAB in complex with increasing doses of traditional additives such as sugar, sodium chloride, certain chemical preservatives and adjustment of $\mathrm{pH}$, all during thermal treatment and storage at freezing conditions. Such studies are useful for understanding the productive use of LAB in food production steps by determining their remaining or decreasing antimicrobial activity in response to technological factors.

\section{Materials and methods Target LAB strains}

This study focuses on twelve lactic acid bacteria (LAB) strains indicated by the possession of enhanced antimicrobial activity by the largest zones of inhibition (ZOI), or some ZOI induced by catalase-treated neutralisates (Table 1) obtained from the Kaunas University of Technology (KTU) Food Institute LAB collection (Kaunas, Lithuania). These are three strains of Lactococcus lactis, two strains of Lactobacillus reuteri (Šalomskienè et al. 2015), two strains of Enterococcus faecium, one strain of Streptococcus thermophilus and four strains of Lactobacillus helveticus.

Table 1. Zones of inhibition of tested LAB against indicator strains

\begin{tabular}{|c|c|c|c|}
\hline \multirow{2}{*}{ LAB species } & \multicolumn{3}{|c|}{ ZOI of cell culture, $\mathrm{mm}$ against } \\
\hline & gram-negative bacteria & gram-positive bacteria & fungi \\
\hline Lactococcus lactis $140 / 2$ & $17-21$ & $15-21$ & 19 \\
\hline Lactococcus lactis 57 & $15-21$ & $13-18$ & 23 \\
\hline Lactococcus lactis $768 / 5$ & $15-21$ & $13-15$ & $11-16$ \\
\hline Lactobacillus helveticus 14 & $17-21$ & $14-18$ & $16-24$ \\
\hline Lactobacillus helveticus 148/3 & $18-19$ & $19-26$ & $14-18$ \\
\hline Lactobacillus helveticus $\mathrm{R}$ & $15-20$ & $20-24$ & 14 \\
\hline Lactobacillus helveticus 3 & $18-19$ & $21-26$ & $19-20$ \\
\hline Lactobacillus reuteri 3 & $16-19$ & $20-30 *$ & $13-16$ \\
\hline Lactobacillus reuteri 7 & $16-19$ & $20-30 *$ & $13-16$ \\
\hline Enterococcus faecium $59 / 30$ & $16-18$ & $17-27^{*}$ & $14-27$ \\
\hline Enterococcus faecium 41/2 & $15-16$ & $17-27^{*}$ & $15-17$ \\
\hline Streptococcus thermophilus 43 & $14-15$ & $18-25^{*}$ & $13-23$ \\
\hline
\end{tabular}

* $=\mathrm{ZOI}$ of cell-free neutralisate after the treatment with catalase was obtained

LAB species identification was based on almost the whole sequence of the $16 \mathrm{~S}$ rDNA gene, which was obtained by PCR using 27F (5'-AGAGTTTGATCCTGGCT CAG-3') and 1492R (5'-GGTTACCTTGTTACGACTT-3') primers. Total genomic DNA was extracted from $1 \mathrm{ml}$ of the broth centrifuged at $900 \mathrm{rpm}$ for $15 \mathrm{~min}$ following the automated sample processing with a QIAcube instrument using a QIAamp stool DNA mini kit (Qiagen, Germany) according to the manufacturer's recommendations.

A total of 100 ng of genomic DNA was used per PCR reaction. DNA samples were quantified using a Thermo Scientific NanoDrop 2000 spectrophotometer (Thermo Fisher Scientific Baltics, Lithuania). Each reaction mixture consisted of $10 \mu$ of $10 \times$ reaction buffer without $\mathrm{MgCl}_{2} ; 1.25 \mathrm{mM}$ of $\mathrm{MgCl}_{2} ; 0.2 \mathrm{mM}$ of (10 mM each) dNTP mix (Thermo Fisher Scientific Baltics, Lithuania); 200 pmol of each primer (Metabion, Germany); $2 \mu$ of $5 \mathrm{ULl}^{-1} \mathrm{recombi}^{-}$ nant Taq DNA polymerase (Thermo Fisher Scientific Baltics, Lithuania) and PCR grade water to a total volume of $100 \mu$ l. 
The reaction conditions were as follows: initial denaturation at $95{ }^{\circ} \mathrm{C}$ for $5 \mathrm{~min}$; 35 cycles at $94{ }^{\circ} \mathrm{C}$ for $1 \mathrm{~min}, 55$ ${ }^{\circ} \mathrm{C}$ for $2 \mathrm{~min}$ and $72{ }^{\circ} \mathrm{C}$ for $2 \mathrm{~min}$. The final extension step was made at $72{ }^{\circ} \mathrm{C}$ for $10 \mathrm{~min}$. PCR amplifications were performed using an Eppendorf Mastercycler 5330 Plus PCR thermal cycler (Eppendorf, Germany). Obtained PCR products were gel purified according to the manufacturer's recommendations using MinElute ${ }^{\circledR}$ Gel Extraction Kit (Qiagen, USA), and sequenced at the Sequencing Centre of the Institute of Biotechnology (Vilnius, Lithuania) with the 3130xlGenetic Analyzer (Applied Biosystems, USA) using a BigDye ${ }^{\circledR}$ Terminator v3.1 Cycle Sequencing Kit (Applied Biosystems, USA). Obtained sequences were analyzed according to Genbank (NCBI).

\section{Screening for modifications of antimicrobial activity}

The influence of technological factors on the modification of antimicrobial activity produced by 12 target LAB strains was determined using an agar well diffusion assay. The indicators used for investigations were reference strains of bacteria Listeria monocytogenes ATCC 19111; Escherichia coli ATCC 25922; Staphylococcus aureus ATCC 25923; Salmonella Typhimurium ATCC 13076; Bacillus cereus ATCC 11778 (Microbiologics, USA) and micromycetes Aspergillus versicolor (Vuill.) Tirab. Mi-Pr-4; Cladosporium herbarum (Pers.) Link ex Gray Sr-11; Penicillium chrysogenum Thom Sr-12, Scopulariopsis brevicaulis (Sacc.) Bainier Mi-Gr-5 from the collection of the Institute of Botany (Vilnius, Lithuania).

For determining antibacterial activity, $0.5 \mathrm{ml}$ of LAB strains (in sterile milk) were cultivated in $10 \mathrm{ml}$ of MRS broth (Oxoid, UK) and incubated for $72 \mathrm{~h}$. Cell-free supernatants (CFS) were obtained by removing cells by centrifugation at $6000 \mathrm{rpm}$ for $15 \mathrm{~min}$ while neutralizates were obtained by adjusting $\mathrm{pH}$ to 6.5 with $1 \mathrm{~mol} \mathrm{l}^{-1} \mathrm{NaOH}$.

The indicator strains were prepared for investigation by transferring them from the PCA slants into $10 \mathrm{ml}$ of buffered peptone solution to obtain the inoculum density of $1.5 \times 10^{7} \mathrm{cfu} \mathrm{ml}^{-1} .1 \mathrm{ml}$ of that suspension was transferred to $100 \mathrm{ml}$ of PCA melted and cooled to $45^{\circ} \mathrm{C}$. The mixture of medium and culture suspension was poured into Petri dishes and allowed to solidify. $7.5 \mathrm{~mm}$ diameter hollows were cut in the agar. $50 \mu$ volume of the tested material was poured into each well of the inoculated plates. Antibacterial activity was indicated by an inhibition zone surrounding the well after incubation for $24 \mathrm{~h}$ at 30 or $37^{\circ} \mathrm{C}$.

\section{Screening for impact of chemical preservatives}

The impact of chemical factors was tested by adding them into the MRS broth. According to the analyzed treatment, concentrations of chemicals were used: 2.0, 5.0, 10.0, 20.0 and 30.0\% of glucose; 2.0, 4.0, 6.5, 8.0 and 18.0\% of $\mathrm{NaCl}$ (Biolife, Germany); $0.05 \%$ of sorbic and benzoic acid; $0.001 \%$ of sodium metabisulphite (Sigma-Aldrich, Germany); $0.01 \%$ of sodium nitrite and $0.015 \%$ of sodium nitrate (Reachem, Slovakia). Concentrations of glucose and $\mathrm{NaCl}$ were chosen according to those used in food products and found in research articles (Pal et al. 2005, Pringsulaka et al. 2012). The concentrations of preservatives were chosen according to the maximum quantities allowed for food preservation by Commission Regulation (EU) No. 1129/2011 on November 112011 . Supernatants were used to determine antimicrobial activity after the growth of target LAB in the MRS broth with appropriate additive for $72 \mathrm{~h}$ at the optimal temperature of the strain $\left(30^{\circ} \mathrm{C}\right.$ or $\left.37^{\circ} \mathrm{C}\right)$.

The impact of the active acidity $(\mathrm{pH})$ on the change of antimicrobial activity was determined by cultivating $L A B$ strains in the MRS broth adjusted to $\mathrm{pH} 4.0,5.0,7.0,8.0$ and 10.0 using solutions of $1 \mathrm{~mol} \mathrm{I}^{-1} \mathrm{HCl}$ or $1 \mathrm{~mol} \mathrm{l}^{-1} \mathrm{NaOH}$. The control treatment of the MRS broth was measured and corresponded to $\mathrm{pH}$ 6.0. After the growth of LAB for $72 \mathrm{~h}$, supernatants and their neutralizates were prepared from each medium and used for evaluation of their antagonistic activity. In all cases, the control samples of freshly prepared CFS were included, which were tested and compared parallelly to an appropriate factor.

\section{Chemical analysis}

The protein amount in CFS was determined by the Kjeldahl method. The method includes the heating of a sample with sulfuric acid using copper (II) sulfate as a catalyst (oxidation liberates the reduced nitrogen as ammonium sulfate). The mixture was alkalized and then the solution was distilled with a small quantity of sodium hydroxide, which converts the ammonium salt into ammonia. The amount of ammonia present, and thus the amount of nitrogen present in the sample, was determined by back titration and nitrogen content was calculated from the amount of ammonia formed. 
The amounts of sorbic and benzoic acids produced by LAB were determined according to ISO 22855 by the highperformance liquid chromatography using a Shimadzu LC - 20AD Prominence equipped with diode array detector and Lab Solutions software. The reversed-phase columns Hydrosphere C18 (5 $\mu \mathrm{m}, 12 \mathrm{~nm}$ ), 150×4.6 I.D. (YMC Co., Ltd., Japan) and Eclipse XDB-C18 $(5 \mu \mathrm{m}), 150 \times 4.6$ (Agilent, USA) were applied. CFS of the tested cultures were clarified with Carrez reagents. The extracts were then filtered through filter paper and a $0.22 \mu \mathrm{m}$ porous filter.

\section{Application of thermal shock and freezing}

The effect of thermal shock on CFS stability was determined by heating it in a water bath at $100{ }^{\circ} \mathrm{C}$ for 5 min, 80 ${ }^{\circ} \mathrm{C}$ for 1 and $10 \mathrm{~min}, 60^{\circ} \mathrm{C}$ for $30 \mathrm{~min}$. One part of CFS was placed into the wells of the agar medium and the other part was neutralized using $1 \mathrm{~mol} \mathrm{I}^{-1} \mathrm{NaOH}$, adjusted $\mathrm{pH}$ to 6.5. It was also placed into the wells for determination of antimicrobial activity.

The stability/change of antimicrobial activity of CFS during storage in a freezer at $-18{ }^{\circ} \mathrm{C}$ and $-72{ }^{\circ} \mathrm{C}$ was determined during storage in both freezers for 3 days, 1 month and 3 months, while antifungal activity was determined during the storage in freezers for 2 and 3 days.

\section{Statistical analysis}

The repeatibility of microbiological and chemical tests was 5 and 3 times, respectively. Standard deviation and ttests were calculated using EXCEL (version 11; Microsoft, USA) software and used to determine the statistically significant difference $(p<0.05)$ between the obtained research results using SPSS v. 16.0 software (IBM, USA).

\section{Results}

\section{Genetic analysis}

Using $16 \mathrm{~S}$ rDNA sequence analysis, species of 12 strains with enhanced antimicrobial properties were confirmed belonging to Lactococcus (Lc.), Lactobacillus (Lb.), Enterococcus and Streptococcus genus (Table 2).

Table 2. LAB species used for investigations and parameters of their $16 \mathrm{~S}$ rDNA sequences indicating the reliability of the identification

\begin{tabular}{|c|c|c|c|}
\hline No. & LAB species & $\begin{array}{l}\text { The resulting sequence identity } \\
\text { to sequences at } \mathrm{NCBI} \text { database, } \%\end{array}$ & $\begin{array}{l}\text { Length of the analyzed } 16 \mathrm{~S} \\
\text { rDNA sequences, bp }\end{array}$ \\
\hline 1 & Lactococcus lactis 140/2 & 95 & 970 \\
\hline 2 & Lactococcus lactis 57 & 99 & 1297 \\
\hline 3 & Lactococcus lactis $768 / 5$ & 99 & 1398 \\
\hline 4 & Lactobacillus helveticus 14 & 94 & 1199 \\
\hline 5 & Lactobacillus helveticus $148 / 3$ & 100 & 1394 \\
\hline 6 & Lactobacillus helveticus $\mathrm{R}$ & 99 & 1341 \\
\hline 7 & Lactobacillus helveticus 3 & 100 & 1114 \\
\hline 8 & Lactobacillus reuteri 3 & 99 & 1428 \\
\hline 9 & Lactobacillus reuteri 7 & 99 & 1494 \\
\hline 10 & Enterococcus faecium 59/30 & 95 & 1406 \\
\hline 11 & Enterococcus faecium 41/2 & 99 & 965 \\
\hline 12 & Streptococcus thermophilus 43 & 98 & 1400 \\
\hline
\end{tabular}

\section{Effect of technological factors on the antimicrobial activity}

The results revealed a broad initial range of $\mathrm{pH}$ 5.0-7.0 as an optimal acidity. Any significant differences were found among LAB antagonistic activity at initial pH 5.0 and pH 7.0 after comparing them to a corresponding activity at control $\mathrm{pH} 6.0$ treatment (Table 3). Antibacterial activity was practically lost and antifungal activity detected only occasionally after adding LAB for cultivating in alkaline media with $\mathrm{pH}$ 10.0. 
The inhibition of antibacterial activity caused by the initial $\mathrm{pH}$ was stronger and more variable against grampositive bacterial species (Table 3).

Table 3. Average zones of inhibition and statistical significance of the treatment effect on antibacterial activity of the analyzed LAB strains

\begin{tabular}{|c|c|c|c|c|c|c|c|c|c|}
\hline \multirow[b]{2}{*}{ Treatment } & & \multicolumn{8}{|c|}{ Average zone of inhibition, $\mathrm{mm}$} \\
\hline & & \multicolumn{3}{|c|}{ Gramnegative bacteria } & \multicolumn{3}{|c|}{ Grampositive bacteria } & \multirow[b]{2}{*}{ total } & \multirow{2}{*}{$\begin{array}{c}\text { Total } \\
\text { bacteria }\end{array}$} \\
\hline factor & level & Ec & St & total & $B C$ & $L m$ & $\mathrm{Sa}$ & & \\
\hline \multirow[t]{5}{*}{$\mathrm{pH}$} & 4.0 & 15 & 15 & 15 & 22 & 22 & 17 & 19 & 18 \\
\hline & 5.0 & 15 & 16 & 16 & 22 & 22 & 18 & 20 & 19 \\
\hline & 7.0 & 15 & 16 & 16 & 23 & 23 & 17 & 20 & 18 \\
\hline & 8.0 & $12 * * *$ & $12 * * *$ & $12 * * *$ & $21 * * *$ & $18^{* * *}$ & $12 * * *$ & $15^{* * *}$ & $14 * * *$ \\
\hline & 10.0 & $1 * * *$ & $1 * * *$ & $1 * * *$ & $1 * * *$ & $2 * * *$ & $1 * * *$ & $1 * * *$ & $1 * * *$ \\
\hline \multirow[t]{5}{*}{ Amount of glucose } & $2.0 \%$ & 16 & 16 & 16 & 22 & 24 & 19 & 22 & 19 \\
\hline & $5.0 \%$ & 17 & 18 & $17^{*}$ & 22 & 23 & 19 & 21 & $20 *$ \\
\hline & $10.0 \%$ & $19 * * *$ & $20 * * *$ & $19 * * *$ & 23 & 24 & 19 & $22^{*}$ & $21^{* * *}$ \\
\hline & $20.0 \%$ & $18^{*}$ & $19 * *$ & $18 * * *$ & 21 & 22 & 17 & 20 & 19 \\
\hline & $30.0 \%$ & $12^{*}$ & 13 & $13^{* *}$ & $13 * *$ & $15^{* * *}$ & $10 * *$ & $13 * * *$ & $14 * * *$ \\
\hline \multirow[t]{5}{*}{ Amount of $\mathrm{NaCl}$} & $2.0 \%$ & $14 *$ & 15 & $15^{*}$ & 19 & 22 & 17 & 19 & $17^{*}$ \\
\hline & $4.0 \%$ & $12^{* * *}$ & $13^{* * *}$ & $12 * * *$ & $14^{*}$ & $18^{* * *}$ & $12 * * *$ & $15^{* * *}$ & $14 * * *$ \\
\hline & $6.5 \%$ & $7 * * *$ & $7 * * *$ & $7 * * *$ & $6 * * *$ & $12 * * *$ & $6 * * *$ & $8 * * *$ & $8 * * *$ \\
\hline & $8.0 \%$ & $5 * * *$ & $6 * * *$ & $6 * * *$ & $5 * * *$ & $7 * * *$ & $4 * * *$ & $5 * * *$ & $6 * * *$ \\
\hline & $18.0 \%$ & $0 * * *$ & $1 * * *$ & $0 * * *$ & $1 * * * *$ & $0 * * *$ & $0 * * *$ & $0 * * *$ & $0 * * *$ \\
\hline Benzoic acid & $0.05 \%$ & 16 & 16 & 16 & 20 & $21^{*}$ & 17 & 19 & 18 \\
\hline Sorbic acid & $0.05 \%$ & 16 & 16 & 16 & 21 & 22 & 17 & 20 & 18 \\
\hline $\begin{array}{l}\text { Sodium } \\
\text { metabisulphite }\end{array}$ & $0.001 \%$ & 14 & 15 & $15^{*}$ & $15^{*}$ & $18^{* *}$ & $12^{*}$ & $15^{* * *}$ & $15^{* * *}$ \\
\hline Sodium nitrite & $0.01 \%$ & 14 & 15 & $15^{*}$ & 19 & $19 * *$ & 15 & $18 * * *$ & $17^{*}$ \\
\hline Sodium nitrate & $0.015 \%$ & 14 & 15 & $14^{*}$ & $17^{*}$ & $20 * *$ & $14^{*}$ & $17^{* * *}$ & $16 * * *$ \\
\hline Control ZOI & & 16 & 16 & 16 & 20 & 23 & 17 & 20 & 18 \\
\hline Number of observat & & 24 & 24 & 48 & 24 & 24 & 24 & 72 & 120 \\
\hline
\end{tabular}

Indicator reference strains: $L m=$ Listeria monocytogenes ATCC 19111, EC = Escherichia coli ATCC 25922, Sa = Staphylococcus aureus ATCC 25923, St = Salmonella Typhimurium ATCC 13076, BC = Bacillus cereus ATCC 11778. ${ }^{*} p<0.05, * * p<0.01, * * * p<0.001$ (comparing the differences between antibacterial activity under the given treatment and control)

The Lactococcus strains managed to exceed antibacterial activity of the tested Lactobacillus strains only while meeting alkaline $\mathrm{pH}$ 8.0. Antifungal activity was similar to antibacterial activity under identical pH levels. It was optimal under $\mathrm{pH}$ 5.0-7.0 and highly variable among the reference species at pH 8.0 (Table 4).

The addition of glucose had the statistically significant effect of both increasing and decreasing antibacterial activity as compared to the control treatment depending on the indicator species and the concentration added (Table 3 ). Adding $30 \%$ of glucose significantly reduced the antibacterial activity against all reference strains. Statistically significant but only slightly enhanced antibacterial activity was revealed in the treatments with glucose supplementation from $5-20 \%$. The addition of $10 \%$ glucose into media enhanced antibacterial activity against the tested gramnegative bacteria. No such obvious increase of ZOI was observed against grampositive bacteria (Table 3).

The best antifungal activity was found when LAB were cultivated with the lowest $2 \%$ of initial glucose (Table 4), but a statistically significant reduction of antifungal activity only occurred in the media containing 20-30\% glucose. No significant differences among the antifungal activity of various LAB species were detected in the initial media with $2-10 \%$ of glucose. Lc. lactis 140/2 and 768/5 formed the largest ZOI against fungi when they had grown in the $2-10 \%$ glucose medium. They retained the most active inhibition (whilst fungistatic) in the $20-30 \%$ glucose medium. 
Table 4. Average zones of inhibition and statistical significance of the treatment effect on antifungal activity of the analyzed LAB strains

\begin{tabular}{|c|c|c|c|c|c|c|}
\hline \multicolumn{2}{|c|}{ Treatment } & \multicolumn{5}{|c|}{ Average zone of inhibition, $\mathrm{mm}$} \\
\hline factor & level & $A v$ & Ch & $P C$ & $S b$ & total \\
\hline \multirow{5}{*}{$\mathrm{pH}$} & 4.0 & $6^{* * *}$ & $1^{* * *}$ & $2 * * *$ & $7^{* * *}$ & $4 * * *$ \\
\hline & 5,0 & 17 & 15 & 14 & 15 & 15 \\
\hline & 7.0 & 18 & 13 & 13 & 14 & $14^{* *}$ \\
\hline & 8.0 & 16 & 14 & $10^{*}$ & $8^{* * *}$ & $12^{* * *}$ \\
\hline & 10.0 & $9 * * *$ & $7^{* * *}$ & $5 * * *$ & $4^{* * *}$ & $6 * * *$ \\
\hline \multirow{5}{*}{ Amount of glucose } & $2.0 \%$ & 17 & 18 & 13 & 17 & 17 \\
\hline & $5.0 \%$ & 17 & 18 & 14 & 16 & 16 \\
\hline & $10.0 \%$ & $11^{*}$ & 18 & 13 & 17 & 15 \\
\hline & $20.0 \%$ & $5^{* * *}$ & $13^{*}$ & $8 * *$ & 16 & $10 * * *$ \\
\hline & $30.0 \%$ & $1^{* * *}$ & $4^{* * *}$ & $3 * * *$ & $11 * * *$ & $4 * * *$ \\
\hline \multirow{5}{*}{ Amount of $\mathrm{NaCl}$} & $2.0 \%$ & 16 & 17 & 14 & 17 & 16 \\
\hline & $4.0 \%$ & 15 & 17 & 12 & 18 & 16 \\
\hline & $6.5 \%$ & 15 & $9^{* * *}$ & $10^{* * *}$ & 18 & $13^{* * *}$ \\
\hline & $8.0 \%$ & $0 * * *$ & $1^{* * *}$ & $6 * * *$ & $12 * * *$ & $5 * * *$ \\
\hline & $18.0 \%$ & $0^{* * *}$ & $1^{* * *}$ & $6 * * *$ & $7 * * *$ & $4 * * *$ \\
\hline Benzoic acid & $0.05 \%$ & $12^{* *}$ & 16 & 15 & $14^{*}$ & $14^{*}$ \\
\hline Sorbic acid & $0.05 \%$ & 15 & 17 & 15 & 15 & 16 \\
\hline $\begin{array}{l}\text { Sodium } \\
\text { metabisulphite }\end{array}$ & $0.001 \%$ & $12^{* *}$ & 16 & $13^{* *}$ & 15 & $14^{*}$ \\
\hline Sodium nitrite & $0.01 \%$ & $10 * * *$ & 15 & 15 & 15 & $14^{*}$ \\
\hline Sodium nitrate & $0.015 \%$ & $14^{* *}$ & 17 & 15 & 17 & 15 \\
\hline \multicolumn{2}{|l|}{ Control ZOI } & 17 & 17 & 14 & 17 & 16 \\
\hline \multicolumn{2}{|l|}{ Number of observation } & 24 & 24 & 24 & 24 & 96 \\
\hline
\end{tabular}

Supplementing the media with $2-18 \% \mathrm{NaCl}$ had a negative effect on overall LAB antibacterial activity. Antibacterial activity was slightly weaker against gramnegative bacteria in the presence of $2 \% \mathrm{NaCl}$ (Table 3 ). Increasing the $\mathrm{NaCl}$ concentration to $6.5 \%$ and above reduced the antibacterial activity more drastically. The antagonistic activity of $L A B$ was practically lost at $18 \%$ of $\mathrm{NaCl}$ in the medium. Adding up to $4 \%$ of $\mathrm{NaCl}$ did not have a significant impact on antifungal activity (Table 4).

The heat treatment regimes $\left(63^{\circ} \mathrm{C}, 30 \mathrm{~min} ; 80^{\circ} \mathrm{C}, 1 \mathrm{~min} ; 80^{\circ} \mathrm{C}, 10 \mathrm{~min} ; 100^{\circ} \mathrm{C}, 5 \mathrm{~min}\right)$ did not show a negative effect on the antibacterial activity of the LAB CFS (Fig. 1a). A statistically significant pattern among investigated LAB has not been found because antibacterial activity decreased irregularly. Heating at high temperature $\left(80^{\circ} \mathrm{C}\right.$ for $10 \mathrm{~min}$ and $100^{\circ} \mathrm{C}$ for $5 \mathrm{~min}$ ) had a greater negative impact than $30 \mathrm{~min}$ at $63^{\circ} \mathrm{C}$ on the antifungal activity of LAB (Fig. $1 \mathrm{~b}$ ). 
(a)

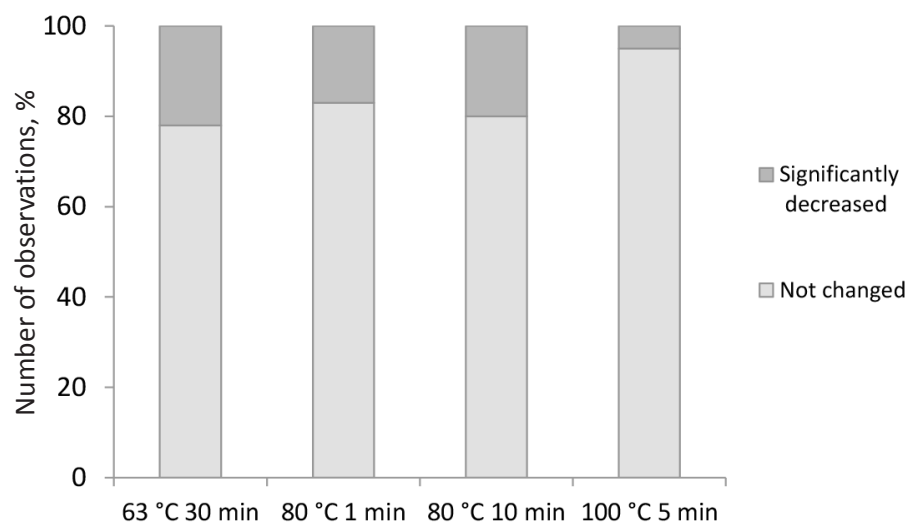

(b)

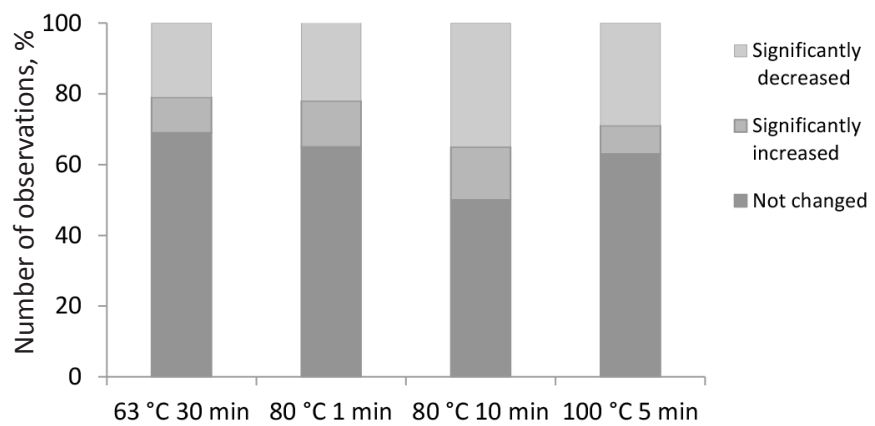

Fig. 1. Changes of antibacterial (a) and antifungal (b) activity during thermal treatment comparing with control points. Number of observations: twelve CFS of LAB cultures vs. five reference bacterial strains $(12 \times 5)(a)$ and twelve LAB vs. four micromycetes foodborne strains $(12 \times 4)(b)$

The antibacterial activity of investigated $L A B$ cultures remained unchanged after freezer storage at $-18{ }^{\circ} \mathrm{C}$ and $-72{ }^{\circ} \mathrm{C}$ from 3 days to 3 months. Freezing at $-18^{\circ} \mathrm{C}$ for 2 or 3 days did not show a negative impact on the antifungal activity of investigated cultures. Freezing at $-72{ }^{\circ} \mathrm{C}$, though, eliminated the antifungal activity or caused it to change from fungicidal to fungistatic.

The application of chemical preservatives in low doses did not have as drastic effect as large amounts of $\mathrm{NaCl}$, glucose or high active acidity. Sodium metabisulphite, sodium nitrite and nitrate reduced overall antagonistic activity of LAB statistically significantly, but only slightly from $18 \mathrm{~mm}$ of control treatment to $16 \mathrm{~mm}, 14 \mathrm{~mm}$ and $15 \mathrm{~mm}$, respectively. Sodium metabisulphite, sodium nitrite and sodium nitrate reduced antibacterial activity against $L$. monocytogenes (Table 3). Sodium metabisulphite and sodium nitrate tended to decrease the inhibition of $B$. cereus and S. aureus. LAB antifungal activity was significantly decreased only against $A$. versicolor in some cases of the tested chemical preservatives except sorbic acid (Table 4). However, the diverse changes of the ZOI caused by chemicals used as preservatives were observed among the LAB strains.

The selection of the best LAB strains retaining their high antimicrobial activity during treatment of technological factors tested against both bacterial and fungal strains are shown in Table 5. 
Table 5. Variety of tested LAB showing their abilities to be used as high antimicrobial activity retaining starter cultures during treatment under the effect of specific technological factor

\begin{tabular}{|c|c|c|c|c|c|c|c|c|}
\hline \multirow{3}{*}{ Tested LAB } & \multicolumn{8}{|c|}{ Technological factor } \\
\hline & \multicolumn{2}{|l|}{$\mathrm{pH}$} & \multicolumn{2}{|l|}{ Glucose } & \multicolumn{2}{|l|}{$\mathrm{NaCl}$} & \multicolumn{2}{|c|}{ Thermal shock } \\
\hline & $\begin{array}{l}\text { Against } \\
\text { bacteria }\end{array}$ & $\begin{array}{l}\text { Against } \\
\text { fungi }\end{array}$ & $\begin{array}{l}\text { Against } \\
\text { bacteria }\end{array}$ & $\begin{array}{l}\text { Against } \\
\text { fungi }\end{array}$ & $\begin{array}{l}\text { Against } \\
\text { bacteria }\end{array}$ & $\begin{array}{l}\text { Against } \\
\text { fungi }\end{array}$ & $\begin{array}{l}\text { Against } \\
\text { bacteria }\end{array}$ & $\begin{array}{l}\text { Against } \\
\text { fungi }\end{array}$ \\
\hline Lactococcus lactis 140/2 & - & + & - & + & - & - & - & + \\
\hline Lactococcus lactis 57 & + & - & + & - & + & + & + & - \\
\hline Lactococcus lactis $768 / 5$ & + & + & + & + & + & - & + & + \\
\hline Lactobacillus helveticus 14 & + & - & + & - & + & + & + & - \\
\hline Lactobacillus helveticus $148 / 3$ & + & - & + & - & + & + & + & - \\
\hline Lactobacillus helveticus $\mathrm{R}$ & + & - & + & - & + & + & + & - \\
\hline Lactobacillus helveticus 3 & + & - & + & - & + & + & + & - \\
\hline Lactobacillus reuteri 3 & - & - & - & - & - & + & - & - \\
\hline Lactobacillus reuteri 7 & - & - & - & - & - & + & - & - \\
\hline Enterococcus faecium 59/30 & - & - & - & - & - & + & - & - \\
\hline Enterococcus faecium $41 / 2$ & - & - & - & - & - & + & - & - \\
\hline Streptococcus thermophilus 43 & - & - & - & - & - & + & - & - \\
\hline
\end{tabular}

- = Antimicrobial activity decreased during the effect of technological factor; + = antimicrobial activity increased or did not change during the effect of technological factor

\section{Production of proteins, sorbic and benzoic acids by tested LAB}

Because $L A B$ strains producing bacteriocins have a significant potential in practical applications, all the 12 selected LAB strains were studied for protein production. Our data revealed 5 strains producing more significant amounts of proteins (Fig. 2). The activity of E. faecium, Lb. reuteri and S. thermophilus against L. monocytogenes was revealed after treating the neutralisate with a catalase. E. faecium and $L b$. reuteri produced higher amounts of proteins compared to the $S$. thermophilus strain but such differences had no noticeable effect on the antibacterial activity.

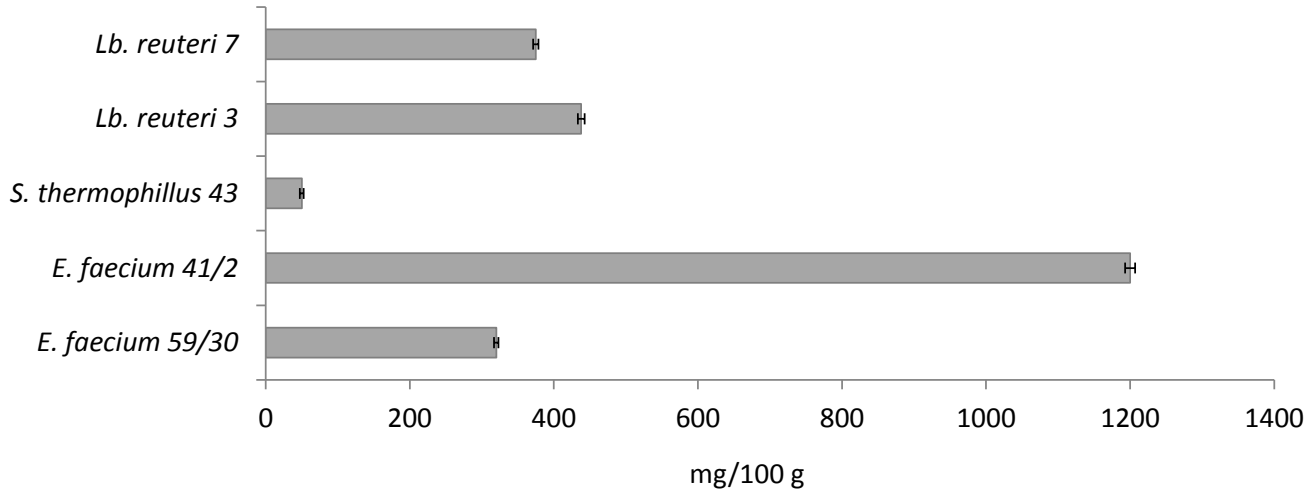

Fig. 2. Protein amounts (mg/100 g) in CFS of lactic acid bacteria

No differences in sorbic acid effect were noticed either among LAB strains naturally producing these compounds or among those not producing LAB strains. Sorbic acid was produced in the amount of $1.20 \pm 0.05 \mathrm{~g} \mathrm{l}^{-1}$ by Lc. lactis $140 / 2$ and $0.10 \pm 0.00 \mathrm{~g} \mathrm{l}^{-1}-$ by $L b$. helveticus $\mathrm{R}$ under the control conditions (when the composition of the MRS medium was not changed). Benzoic acid was naturally secreted by all analysed LAB strains in MRS media ranging from $0.20 \pm 0.02 \mathrm{~g} \mathrm{l}^{-1}(\mathrm{Lb}$. reuteri 3 and 7$)$ to $1.80 \pm 0.34 \mathrm{~g} \mathrm{l}^{-1}(\mathrm{Lb}$. helveticus 22$)$. However, the complete loss of activity against $A$. versicolor by $L b$. helveticus 22 was observed after benzoic acid was added into the medium. $L c$. lactis 140/2 (1.50 $\left.\pm 0.31 \mathrm{~g} \mathrm{l}^{-1}\right)$ maintained high antifungal activity under identical conditions (Table 3). The reduction in antibacterial activity against L. monocytogenes was indicated by Lc. lactis 140/2 and 768/5 (with natural production of benzoic acid of $0.40 \pm 0.02 \mathrm{~g} \mathrm{l}^{-1}$ ) and $S$. thermophilus 43 (with natural production of benzoic acid $0.50 \pm 0.08 \mathrm{~g} \mathrm{l}^{-1}$ ). Thus, the changes in antifungal activity against $A$. versicolor, S. brevicaulis and antibacterial activity against $L$. monocytogenes caused by chemicals used as preservatives were highly strain dependant and not associated with their natural ability to produce benzoic or sorbic acids under the control conditions. 


\section{Discussion}

LAB are known to produce the whole range of antagonistic substances, including organic acids, diacetyl, hydrogen peroxide, ethanol, acetaldehyde, acetoine, carbon dioxide, bacteriocins (reuterin, reutericyclin), bactericidal proteins and other antagonistic compounds. The analysed LAB strains showed good antagonistic activity under the broad range of $\mathrm{pH}(4-8)$ and initial glucose amounts (2-10\%). Carefully regulated amounts of glucose given the maximal values in antibacterial activity possibly because of affecting the speed of changes in $\mathrm{pH}$ (Mercier et al. 2007) during LAB fermentation. The antagonistic activity was lost in many cases dealing with $L A B$ neutralisate. In a few cases the neutralisates were acting against L. monocytogenes, E. coli, S. aureus and B. cereus. LAB are generally known as acid-tolerant bacteria capable of inducing an antimicrobial effect attributable to the drastic lowering of $\mathrm{pH}$. Such results were confirmed by our results under all chemical treatments.

It has been previously reported that the LAB isolates from cabbage and sheep excreta grew at pH 2.5 (Aswathy et al. 2008). E. faecium strain $1 \mathrm{LC}$ has been reported as the best strain resistant to pH 3.0 (Bakari et al. 2010). But the significant loss in antibacterial and especially in antifungal activity of both $E$. faecium strains was observed at pH 4.0 in our study (Table 3).

Different species of LAB were employed during fermentation of dairy products due to their probiotic potential (Hati et al. 2013). Among those species, Lc. lactis, S. thermophilus and Enterococcus spp. were examined in our study as well. $L b$. reuteri examined in our study showed exclusive adaptation to an acidic environment. Both examined $L b$. reuteri strains showed the best antibacterial activity at $\mathrm{pH} 4.0$. Each of them was found producing bacteriocin like substances active against $L$. monocytogenes. These strains were good at inhibiting the growth of $B$. cereus as well. The addition of chemical preservatives is broadly applied in food production. Some of them could still not be completely decomposed in the human gut and faced by the present probiotic bacteria. Thus, no significant effect of chemical preservatives on LAB starters with the probiotic potential can be expected. Our results revealed the significant effect of the tested chemical preservatives in some cases (such as both $E$. faecium strains or $L b$. reuteri strains, Lc. lactis 57 ). Further examination in more detail is needed to reveal the possible effect of chemical preservatives on probiotic LAB strains consumed with food. We have analysed the effect on the antibacterial or antifungal effect of the chemical preservatives only under the optimal conditions in vitro. This effect could be shaped by differences in the chemical environment of the human gut.

The contradicting information about the changes in LAB antifungal activity due to variation in the chemical environment was observed. The importance of $\mathrm{pH}$ on the antifungal activity was demonstrated by the other studies (Sathe et al. 2007, Elsanhoty 2008). A similar range of pH 5.0-7.0 favourable for inducing antifungal activity was detected by Reddy and Ranganathan (1985) and Corsetti et al. (1998). However, Lb. coryniformis subsp. coryniformis strain Si3 produced antifungal protein active at $\mathrm{pH}$ values of between 3.0 and 4.5. It decreased rapidly when pH was adjusted to a level between 4.5 and 6.0 and was lost at higher pH values (Magnusson and Schnürer 2001). This suggested that the loss of high antifungal activity at acidic environment depended on the species or strain.

A sudden increase in antifungal activity, especially against $S$. brevicaulis, was observed in some cases after the addition of initial glucose (for $10 \%$ induced by E. faecium $59 / 30 ; 2 \%$ - by S. thermophilus $43,2 \%-$ for $\mathrm{Lb}$. helveticus $3,2-5 \%$ - for $L b$. helveticus 148/3) and $\mathrm{NaCl}$ (2-4\% induced by Lc. lactis 140/2 and Lb. helveticus 3). In accordance with our results, the increase of glucose concentration (to 1-2\%) and increase in $\mathrm{NaCl}$ (to $0.5-3 \%$ ) led to a higher antifungal efficiency of P. acidilactici, Lb. rhamnosus as well (Effat et al. 2001).

However, in many other cases even the lowest amount of $2 \% \mathrm{NaCl}$ reduced LAB antagonistic activity. This could be caused by some negative effect of $\mathrm{NaCl}$ on the bacterial growth. The presence of $1.8-2.2 \%$ of $\mathrm{NaCl}$ was able to inhibit many LAB strains as has been found in sauerkraut (Serrazanetti et al. 2013). In spite of that, LAB generally were discussed as tolerant to high $\mathrm{NaCl}$ concentrations up to 8-12\% (Aswathy et al. 2008). About half of the selected strains grew well and maintained some antibacterial activity in the presence of $8 \% \mathrm{NaCl}$ in our experiment. Only 5 strains were able to inhibit at least half of the fungal species. E. faecium $41 / 2$ and $L b$. helveticus strain 14 revealed a tolerable antibacterial and antifungal activity while facing $8 \%$ of sodium chloride. LAB isolated from the special environment (such as bakasang, an Indonesian traditional fermented fish product) were able to grow at up to $10 \%$ of $\mathrm{NaCl}$, but failed to grow at $18 \%$ of $\mathrm{NaCl}$ (Lawalata et al. 2011) as in the case of our studied starter cultures. The ability of $\mathrm{LAB}$ to withstand a high $\mathrm{NaCl}$ concentration may be very important in some cases. For example, commercially preserved cucumbers, natural fermenting in $5 \%$ to $8 \%$ brines, could occasionally spoil after the primary fermentation is complete because of the decrease in lactic acid and a rise in brine $\mathrm{pH}$ caused by microbial instability (Johanningsmeier et al. 2012). 
In order to maintain foods with almost unchanged properties for a longer period, the heat treatment (most often pasteurization or, in some cases, sterilization) of raw materials or semi-finished products is used. The antimicrobial activity of LAB, their stability and changing, depended on the type of LAB species and the species of tested reference strains. Ponce et al. (2008) found that after heating for 10 and $20 \mathrm{~min}$ at $60^{\circ} \mathrm{C}$ and $80^{\circ} \mathrm{C}$, the antimicrobial activity of $L c$. lactis supernatant decreased by approximately $40 \%$. Heating for $5 \mathrm{~min}$ at $100^{\circ} \mathrm{C}$ had a great influence on the antibacterial activity of $L$ c. lactis $768 / 5$ against $L$. monocytogenes and S. aureus and Lc. lactis 57 against S. aureus. On the other hand, Campos et al. (2006) found that bacteriocin produced by Lc. lactis, after heating for $60 \mathrm{~min}$ at $100{ }^{\circ} \mathrm{C}$ remained stable and had an antimicrobial activity against $L$. monocytogenes and S. aureus. Heating time affected the stability of antimicrobials: the activity of antimicrobial substances decreased with increased heating time. During the storage in a freezer, LAB culture supernatants had antagonistic properties against the corresponding tested reference strains. The results obtained show the potential application of tested LAB with antimicrobial properties in technological processes. Recently, the demand for frozen foods is increasing. The selected LAB strains could be effectively used as natural preservatives that will retain antimicrobial activity during freezing. Similar results were presented in the scientific literature. Rushdy and Gomaa (2013) found that the bacteriocin-like substance produced by L. brevis, remains stable after $24 \mathrm{~h}$ of freezing at $-20^{\circ} \mathrm{C}$. The cell culture supernatants of E. faecium, LC. lactis, E. hirae and E. canis retained an antimicrobial activity against the tested microorganisms after storage for 15 days at $5{ }^{\circ} \mathrm{C}$ and after freezing for 1 day at $-20^{\circ} \mathrm{C}$ (Ponce et al. 2008).

We failed to find any studies reporting the effect of chemical food preservatives in low doses on LAB for comparison. However, the organic acids including such acids as acetic, lactic, propionic, sorbic and benzoic are broadly applied in food preservation (Brul and Coote 1999). Both sorbic and benzoic acid suppress many harmful microorganisms (Nielsen and de Boer 2000, Davidson 2001). They are known as good antifungal agents. The addition of sorbic or benzoic acid caused no significant increase in antimicrobial activity.

Determining exposure in antagonistic activity of LAB by their response to technological factors is important for practical application. Selection of tested LAB revealed their possibilities to use them for specific food production. Only one starter culture, Lc. lactis $768 / 5$, showed a high stable antimicrobial activity during all investigated technological factors against both reference bacterial and fungal strains. Thus, combining LAB with chemical preservatives or thermal treatment/freezing has a potential to improve safety and/or shelf life of food products by additionally maintaining natural antagonistic activity of $L A B$ against the broad range of indicator species. The preliminary studies have already shown that investigated LAB produce plain of antimicrobial compounds.

\section{Conclusions}

Tested lactic acid bacteria cultures demonstrated a strong antimicrobial activity mostly specialised against one indicator species during treatment of technological factors. All Lactobacillus helveticus strains and Lactococcus lactis 57 could be used as starter cultures retaining their high antimicrobial activity at pH 4-8, glucose 2-20\%, sodium chloride $2-6.5 \%$ in the medium, after thermal shock and freezing against indicator strains mostly found in foods. Lactococcus lactis 768/5 was superior in retaining high antimicrobial activity against a whole complex of the indicator species, while only Lactococcus lactis 140/2 displayed a high antifungal activity during the treatment of all tested technological parameters. The results demonstrated that individual lactic acid bacteria cultures may vary in antibacterial and antifungal activities against the indicator species and offer different possibilities in selecting strains for use in food production.

\section{Acknowledgements}

We greatly acknowledge financial support from the Research Council of Lithuania, grant SVE-05/2012 PIENRUGBAKT.

\section{References}

Aswathy, R.G., Ismail, B., John, R.P. \& Nampoothiri, K.M. 2008. Evaluation of the Probiotic Characteristics of Newly Isolated Lactic Acid Bacteria. Applied Biochemistry and Biotechnology 151: 244-55.

Bakari, D., Tatsadjieu, N.L., Mbawala, A. \& Mbofung, C.M. 2010. Assessment of physiological properties of some lactic acid bacteria isolated from the intestine of chickens use as probiotics and antimicrobial agents against enteropathogenic bacteria. Innovative Romanian Food Biotechnology 8: 33-40.

Blagojev, N., Škrinjar, M., Vesković, S., Morač, S.A. \& Šošo, V. 2012. Control of mould growth and mycotoxin production by lactic acid bacteria metabolites. Romanian Biotechnological Letters 17: 7219-7226.

Brul, S. \& Coote, P. 1999. Preservative agents in foods. Mode of action and microbial resistance mechanisms. International Journal of Food Microbiology 50: 1-17. 
Çakir, I. 2010. Antibacterial and antifungal activities of some lactic acid bacteria isolated from naturally fermented herbs. Journal of Food Agriculture and Environment 8: 223-226.

Campos, C.A., Rodríguez, Ó., Calo-Mata, P., Prado, M. \& Barros-Velázquez, J. 2006. Preliminary characterization of bacteriocins from Lactococcus lactis, Enterococcus faecium and Enterococcus mundtii strains isolated from turbot. Food Research International 39: 356-364.

Corsetti, M., Gobetti, J., Rossi, J. \& Damiani, P. 1998. Antimould activity of sourdough lactic acid bacteria: identification of a mixture of organic acids produced by Lactobacillus sanfrancisco CB1. Applied Microbiology and Biotechnology 50: 253-256.

Davidson, M.P. 2001. Chemical preservatives and natural antimicrobial compounds. In: Doyle, M.P., Beuchat, L.R. \& Montville, T.J. (eds.). Food microbiology: Fundamentals and frontiers. Washington, USA: ASM press. p. 593-627.

Effat, B.A., Ibrahim, G.A., Tawfik, N.F. \& Sharaf, O.M. 2001. Comparison of antifungal activity of metabolites from Lactobacillus rhamnosus, Pediococcus acidilactici and Propionibacterium thoenii. Egyptian Journal of Dairy Science 29: 251-262.

Elsanhoty, R.M. 2008. Screening of some lactobacillus strains for their antifungal activities against aflatoxin producing aspergilli in vitro and maize. Journal of Food Agriculture and Environment 6: 35-40.

Gálvez, A., Abriouel, H., López, R.L. \& Omar, N.B. 2007. Bacteriocin-based strategies for food biopreservation. International Journal of Food Microbiology 120: 51-70.

GenBank", NCBI, Bethesda, MD, USA: http://www.ncbi.nlm.nih.gov/.

Ghaly, A.E., Dave, D., Budge, S. \& Brooks, M.S. 2010. Fish Spoilage Mechanisms and Preservation Techniques: American Journal of Applied Sciences 7: 859-877.

Hati, S., Mandal, S. \& Prajapati, J.B. 2013. Novel Starters for Value Added Fermented Dairy Products. Current Research in Nutrition and Food Science 1: 83-91.

Johanningsmeier, S.D., Franco, W., Perez-Diaz, I. \& McFeeters, R.F. 2012. Influence of Sodium Chloride, pH, and Lactic Acid Bacteria on Anaerobic Lactic Acid Utilization during Fermented Cucumber Spoilage. Journal of Food Science 77: 397-404.

Lawalata, H.J., Sembiring, L. \& Rahayu, E.S. 2011. Molecular Identification of Lactic Acid Bacteria Producing Antimicrobial Agents from Bakasang, An Indonesian Traditional Fermented Fish Product. Indonesian Journal of Biotechnology 16: 93-99.

Lucera, A., Costa, C., Conte, A. \& Del Nobile, M.A. 2012. Food applications of natural antimicrobial compounds. Frontiers in Microbiology 287: 1-13.

Magnusson, J. \& Schnürer, J. 2001. Lactobacillus coryniformis subsp. coryniformis Strain Si3 Produces a Broad-Spectrum Proteinaceous Antifungal Compound. Applied and Environmental Microbiology 67: 1-5.

Mercier, P., Yerushalmi, L., Rouleau, D. \& Dochain, D. 2007. Kinetics of lactic acid fermentation on glucose and corn by Lactobacillus amylophilus. Journal of Chemical Technology \& Biotechnology 55: 111-121.

Nielsen, P.V. \& de Boer, E. 2000. Food preservatives against fungi. In: Samson, R.A., Hoekstra, E.S., Frisvad, J.C. \& Filtenborg, O. (eds.). Introduction to food- and airborne fungi. Washington, DC : ASM Press. p. 357-363.

Pal, V., Jamunaand, M. \& Jeevaratnam, K. 2005. Isolation and characterization of bacteriocin producing lactic acid bacteria from a South Indian special Dosa (Appam) batter. Journal of Culture Collections 4: 53-60.

Ponce, A.G., Moreira, M.R., del Valle, C.E. \& Roura, S.I. 2008. Preliminary characterization of bacteriocin-like substances from lactic acid bacteria isolated from organic leafy vegetables. Food Science and Technology 41: 432-441.

Pringsulaka, O., Thongngam, N., Suwannasai, N., Atthakor, W., Pothivejkul, K. \& Rangsiruji, A. 2012. Partial characterisation of bacteriocins produced by lactic acid bacteria isolated from Thai fermented meat and fish products. Food Control 23: 547-551.

Reddy, N.S. \& Ranganathan, B. 1985. Effect of time, temperature and $\mathrm{pH}$ on the growth and production of antimicrobial substance by Streptococcus lactis ssp diacetylactis S1-67-C. Milchwissenshaft 40: 346-348.

Rushdy, A.A. \& Gomaa, E.P. 2013. Antimicrobial compounds produced by probiotic Lactobacillus brevis isolated from dairy products. Annals of Microbiology 63: 81-90.

Sathe, S.J., Nawani, N.N., Dhakephalkar, P.K. \& Kapadnis, B.P. 2007. Antifungal lactic acid bacteria with potential to prolong shelflife of fresh vegetables. Journal of Applied Microbiology 103: 2622-2628.

Schnürer, J. \& Magnusson, J. 2005. Antifungal lactic acid bacteria as biopreservatives. Trends in Food Science \& Technology 16: 70-78.

Serrazanetti, D.I., Gianotti, A., Montanari, C. \& Gottardi, D. 2013. Dynamic Stresses of Lactic Acid Bacteria Associated to Fermentation Processes. INTECH Open Access Publisher 539-570. http://www.intechopen.com/books/lactic-acid-bacteria-r-d-for-foodhealth-and-livestock-purposes/dynamic-stresses-of-lactic-acid-bacteria-associated-to-fermentation-processes. Accessed 11 November 2014

Smaoui, S., Elleuch, L., Bejar, W., Karray-Rehai, I., Ayadi, I., Jaouadi, B., Mathieu, F., Chouayekh, H., Bejar, S. \& Mellouli, L. 2010. Inhibition of fungi and gram-negative bacteria by bacteriocin BacTN635 produced by Lactobacillus plantarum sp. TN635. Biotechnology and Applied Biochemistry 162: 1132-1146.

Stoyanova, L.G., Ustyugova, E.A., Sultimova, T.D., Bilanenko, E.N., Fedorova, G.B., Khatrukha, G.S. \& Netrusov, A.I. 2010. New Antifungal Bacteriocin-Synthesizing Strains of Lactococcus lactis ssp. lactis as the Perspective Biopreservatives for Protection of Raw Smoked Sausages. American Journal of Agricultural and Biological Sciences 5: 477-485.

Šalomskienė, J., Abraitienè, A., Jonkuvienė, D., Mačionienè, I. \& Repečkienė, J. 2015. Selection of enhanced antimicrobial activity posing lactic acid bacteria characterised by (GTG)5-PCR fingerprinting. Journal of Food Science and Technology 52: 4124-4134.

Theron, M.M., Lures, J. \& Rykers, F. 2010. Application of organic acid in food preservation. In: Theron, M.M. \& Rykers Lues, J.F. (eds). Organic Acids and Food Preservation. Boca Raton: CRC Press. p. 51-95. 